in consequence of the cessation of the afflux of blood, there is no reason why this should not occur in cases such as this, when the circulation is at a standstill, and the functions of the nervous system are in abeyance.

It is to be noted that rigor mortis attacks the skin, and causes cutis anserina; but in this case the skin was at any rate only partially affected, for it was quite flaccid, though unlike the normal skin. I may also mention, as a point of interest, that the case was one of acute starvation, without wasting.

Stainton Lodge, Blackheath, S.E.

\section{CASE OF RABIES, WITH UNUSUAL FEATURES.}

\section{BY MARK H. H. VERNON, L.R.C.P. \&c.}

I THINK that the following case is of sufficient importance to deserve record.

I saw, on the night of May 23rd, a gamekeeper, aged twenty, a man of intemperate habits, about whom the following history was given me:-Some time at the end of February, or the beginning of March, while trying to separate three small terriers, which were quarrelling, he was bitten by one of them on the calf of the leg. He was wearing a leather gaiter, and the dog's teeth did little more than break the skin of his leg. The wound appears to have caused him no trouble or anxiety. He seems to have had some worry from other causes, and to have indulged freely in beer.

On May 19th he was returning home from work in company with a friend, and was suddenly taken in a "fit." The man in whose company he was states that the patient, without any warning, suddenly lay down on the ground, and began to kick and bite at everything around him, that he seemed at first to be choking, and began to "bark like a dog." Some water was given him in a metal cup, out of which he bit two pieces, and he could not swallow the water. He continued to kick and bite and struggle for rather more than an hour; he then became quiet again, and seemed in his usual state of health, and continued so until three days after, when he began to complain of violent toothache, from which he had never previously suffered, so far as I could learn. At about six o'clock on the evening of the same day, as he was going his rounds with one of his mates, he told his companion that he was going to get a drink at a pond close by. He did not return, and the other keeper on going to look for him found him partly in the water, making a hoarse grunting noise, biting at the rushes, and, as he phrased it, "fighting" the water. He pulled him out, on which the man drew a knife from his pocket, and seemed to wish to cut his throat. The knife was taken from him, and then he became very violent, kicking and biting at all who came near. When water was brought to him, he said that it burnt him, and he could not swallow it. The messenger who came for me told me that I was wanted to see a man gone mad with toothache. I saw the man nearly three hours after he was first seized. I found him lying on the ground, held by five or six men. His face was flushed, and had a terrified expression. Eyes bright and staring, with injected conjunctivæ; pupils equal and contracted. The angles of the mouth were retracted. There was no trismus, and no particular hardness about the muscles of the neck. He was constantly snapping at the air, and if a hand was placed near his mouth he tried to bite it. He kept hawking and spitting up frothy mucus. Breathing short and hurried; skin dry and tolerably cool; temperature could not be taken; pulse hard and wiry.

I had him put into a cart and taken home. This was a work of some difficulty; his struggles were so great that it required several men to hold him. As soon as he was in bed I gave him two drops of croton oil and injected half a grain of morphia subcutaneously. In a short time, although still apparently unconscious of all that was going on around him, he tried to say something which was construed into a request for water. He swallowed a little drop, and then a spasm seized him ; he seemed to be choking, and again became very violent, hawking and spitting as before. In an hour and a half, as the morphia seemed to have had no effect whatever, I gave him a second hypodermic injection, not quite so large as before (about one-third of a grain). In three-quarters of an hour he was much more composed, and again tried to ask for water. The effect was the same as before, but did not last so long. When he became quiet again, I left him, giving careful directions to his attendants to keep him perfectly undisturbed if possible.

I saw him early the next morning, and found him quite unconscious and in a moribund condition. I was told that he slept for two hours and a half after I left him; that he then woke up and said he knew he was going to die. $\mathrm{He}$ recognised all his relations and talked to them quietly. After a time he asked for water; this was brought him; he swallowed a little, but it then seemed to choke him. He became violent again - biting, hawking, and spitting as before. After struggling for an hour or two, he seemed to become exhausted. He died fourteen hours after the second seizure, and four days and a half after the first. There was no autopsy.

There can be no doubt that this case was one of rabies, and I think there are several noteworthy points in it:1. The dog was not mad, and, up to the time of the man's death, had shown no signs of madness; it was only angry. 2. The bite was inflicted through a thick gaiter, thus minimising the chances of inoculation. 3 . If the patient's friends are to be relied on, at least three clear days elapsed between the first and second seizures. Making all allowances for vivid imaginations and inexact recollections, yet the fragments of a pewter cup remain to show that the man must have been in an unusual frame of mind when he made use of the cup.

Horsham.

\section{ACCUMULATION OF CERUMEN SIMULATING CHRONIC BRONCHITIS.}

BY J. RUDD LEESON, M.B.,

LATE DEMONSTRATOR OF ANATOMY, ST. THOMAS'S HOSPITAL.

MRs. V — had suffered at intervals of from three to five years from several attacks of acute and subacute hronchitis, from which she recovered, her lungs being left fairly free from physical signs, but which slowly then increased, much to her distress, and defied all treatment. She had a violent morning cough, lasting oftentimes nearly an hour, and terminating with vomiting about half a teaspoonful of glairy mucus. So severe was this morning cough that she dreaded rising, having generally to rest several times during dressing, from exhaustion. The bowels and bladder were relieved almost involuntarily. All sorts of plans, schemes, and medicines were tried, but without success, and I abandoned her case as being a hopeless one of chronic bronchitis.

For about two years she had suffered from increasing deafness, and had almost lost hearing on one side. Lately she began to complain of the good ear becoming affected and one morning I was called to see her on account of almost complete deafness. On examination, both ears were filled with inspissated cerumen, which, after much syringing and soaking with oil, was removed, and her hearing was com. pletely restored. From that day she has entirely lost her cough and sickness, and appears indeed to be quite another woman. Now this is a most interesting fact, and I venture to bring it before the notice of the medical profession, hoping that perhaps other cases of so-called "chronic bronchitis" may be cured with like rapidity.

Accumulation of cerumen in the ears and chronic bronchitis both chiefly affect those advanced in life. It may be that a connexion between the two as cause and effect has hitherto been overlooked. However, in any case of prolonged and troublesome cough which resists the ordinary remedies, I should advise a careful examination to be made with a speculum of the external auditory canal, it being almost needless to say that a considerable accumulation of wax may exist without damaging the hearing to any marked extent.

The explanation of the case is now easy : the cough was simply a reflex one. All aural surgeons are familiar with the fact that foreign bodies in the ear are frequently attended with a dry cough. Physiologists also know that coughing can be excited by tickling the auditory canal. In this case the stimulus seems to have travelled down the 